\title{
Epica y Misoginia en Los Hombres de a Caballo
}

La tradición literaria de occidente destaca el viaje como vehículo temático y recurso estructural, desde la épica clásica; es decir, desde los inicios de lo que pudiera concebirse como narrativa, el héroe abandona la tierra de su nacimiento, el hogar materno o matrimonial, para cumplir una misión, llevar a cabo una aventura, periplo arquetípico trazado inicialmente por alguna deidad. ${ }^{1}$ Del reparto de papeles que la tradición clásica hace en casos tales (hombre activo, heroico; mujer pasiva, doméstica) emerge ya un incipiente antifeminismo que se extiende a lo largo de toda la tradición narrativa occidental. Antifeminismo complejo, dialéctico, ya que después de su aventura el héroe ha de intentar regresar al hogar y a la mujer. Tanto este recurso del viaje como la misoginia que conlleva se manifiestan con insistencia en la literatura gauchesca. La reciente novela de David Viñas, Los hombres de a caballo, los resucita a ambos, pero con un propósito distinto y novedoso.

El tipo social que hacia 1790 recibe el nombre de "gaucho" era "el vagabundo, el cuchillero, el alzado contra la autoridad, el cuatrero", ${ }^{2}$ gente que por razones evidentes debía mantenerse en continuo movimiento. Los gauchos que salen de la pluma de Bartolomé Hidalgo y la de Hilario Ascasubi son partícipes en esa realidad agitada y móvil, propia de la lucha independentista y antirosista respectivamente. Otros ejemplos más conocidos son el viaje a Buenos Aires del gaucho Anastasio el Pollo, en el Fausto; los personajes que pueblan y recorren la pampa en el Facundo de Sarmiento, la persecución del protagonista de Aventuras de un centauro de la América meridional, y especialmente las aventuras de Martín Fierro, quien en la primera parte del poema de Hernández-la "Ida"-abandona mujer e hijos y se va al desierto. Don Segundo

1 Mircea Eliade, The Myth of the Eternal Return. (New York: Pantheon, 1954), p. 27.

${ }^{2}$ Enrique Anderson Imbert, Historia de la literatura hispanoamericana. (México: Fondo de Cultura Económica, 1970), vol. I, p. 212. 
Sombra, al marcar el apogeo de la tradición gauchesca, da mayor relevancia al tema del viaje, destacando precisamente sus características más clásicas: el joven que desconociendo su identidad, su linaje, "camina por las vastas soledades del mundo obedeciendo a un impulso que le conduce a la presentida realización de su destino". ${ }^{3}$ Sin embargo, después que el joven ha superado todas las "pruebas" que su viaje le depara, de haber aclarado el misterio de su orfandad, y alcanzado como recompensa a sus tribulaciones el rango de estanciero, no nos encontramos ni Elena ni Penélope a la manera clásica. De hecho, de las mujeres con que ha tenido contacto el protagonista Favio sólo dos reciben mínima atención en la novela: 1) la "chinita" del maizal, la "chinita querendona", " que no es más que un entretenimiento fugaz, rayando casi en la violación, y 2) Paula, la chica que le atiende después de haber sido herido por el toro, y de la cual el joven se va enamorando muy a pesar suyo: "¿Qué puede hacer un hombre en tal situación y para qué sirve un gaucho que se deja ablandar por esas querencias?" 5 Más tarde, cuando involuntariamente la muchacha se convierte en causa de su pelea con Numa, Fabio la culpa y se aleja de ella, recurriendo al estoicismo (en parte misógino) aprendido de la pampa: " 'Hacete duro, muchacho', me había dicho una noche don Segundo, asentándome un rebencazo por las paletas"' (p. 204).

- La negación de Favio a "volver hacia atrás" cuando se aleja de la joven, o después de llegar a ser hacendado, su intransigencia a efectuar el regreso clásico hacia la amada, la falta de una influencia femenina más perdurable que la "chinita querendona", aparta en cierto modo la obra de Güiraldes de la tradición clásica. El misoginismo de la literatura gauchesca es una exageración de la corriente épica tan radical que llega a negarla. Lo que caracteriza a don Segundo es su dureza; don Segundo nunca ha necesitado a nadie, especialmente a mujeres. Muy parecida es la situación del segundo tutor de Favio, el estanciero don Leandro Galván, quien, aunque tiene un hijo (Raucho), no aparece nunca vinculado a ninguna. mujer.

En Güiraldes, la.misoginia parece estar relacionada al mensaje que ha querido imprimirle a la novela; o sea, la misión que pueden y deben desempeñar los hombres que se han "hecho duros" en las faenas de la tierra: "El que sabe de los males de esta tierra por haberlos vivido se ha templado para domarlos" (p. 276). Es la mentalidad del pionero que todo lo abandona-inclusive un mínimo de ternura femenina-ante la necesidad de lanzarse a la lucha para subyugar a

3 Fernando Alegría, Historia de la novela hispanoamericana (México: Ediciones de Andrea, 1966), p. 184.

4 Ricardo Güiraldes, Don Segundo Sombra. (México: Diana, 1964), p. 65.

5 Ibid., p. 198. Se nota aquí una alteración de la perspectiva hacia una mayor omnisciencia. Tal parece como si este nuevo narrador, adulto, se mofara de la sentimentalidad del gauchito: sólo los jóvenes inexpertos se enamoran.

En el resto de las citas textuales de Don Segundo Sombra simplemente se mencionará la página. 
una naturaleza siempre vista como una fuerza femenina caótica y amenazadora. Es la visión que predomina, por ejemplo, en $L a$ vorágine de Rivera; aquello que es particularmente hispanoamericano y que tal vez explique el exagerado misoginismo de la tradición gauchesca. En la narrativa hispanoamericana, al igual que en el mundo clásico (en Los siete contra Tebas, por ejemplo), la invasión foránea de la madre patria se considera una violación; podría decirse que la tan reiterada épica del sometimiento de la naturaleza americana al hombre descendiente del conquistador español sea también en el fondo la historia de una violación. El incesto edípico subyacente en la violación genera esa misoginia ya mencionada, dialéctica análoga a la observada por Octavio $\mathrm{Paz}$ en su Laberinto de la soledad con respecto a la "chingada". Es decir, tal vez el regreso, ausente en la superficie del texto, exista ya como condición primaria en el sometimiento de la naturaleza.

En Los hombres de a caballo desembocan los temas del viaje y la misoginia siguiendo el cauce de la tradición gauchesca. Pero el tono y la intención han cambiado radicalmente. No se trata ya del sometimiento de América por unos héroes épicos - fábula propiciada por el positivismo liberal y burgués que anima la novela criollista - , sino la parodia de ese sometimiento y de esos héroes.

En la novela de Viñas aparece el viaje en un vuelo de Buenos Aires a Lima realizado en 1965 por un escuadrón de caballería del ejército argentino, que-junto a otros contingentes militares hispanoamericanos-participará en los ejercicios bélicos denominados "Operativo Ayacucho". ${ }^{6}$ A la par de este viaje espacial en que toma parte el protagonista Emilio Godoy, puede observarse otro viaje más sutil y significativo: un viaje temporal hacia las raíces genealógicas del personaje. Desfilan ante el lector su hermano mayor, su tío, el padre, el abuelo, el bisabuelo y hasta el tatarabuelo; pero no en ese orden-ni tampoco a la inversa-, sino mediante una técnica fragmentaria, rica en flashbacks, monólogos interiores y jirones de fluir psíquico de los belicosos miembros de la estirpe Godoy. De ese modo el pasado se incorpora al presente en una forma discontinua, creando la sensación de un "presente en crecimiento". ${ }^{7}$ Esa ilusión

6 David Viñas, Los hombres de a caballo. (México: Siglo XXI Editores, 1968), p. 53. La operación es aparentemente ficticia, aunque existen varios antecedentes históricos a lo largo de 1965. En abril, muy precipitadamente se organiza la Fuerza Interamericana de Paz para prestar ayuda político-militar a las fuerzas intervencionistas de Estados Unidos en Santo Domingo. En agosto, los jefes militares centroamericanos acuerdan la creación del Consejo de Defensa Centroamericana ("Integración militar: La defensa centroamericana", Visión, vol. 29, no. 7, p. 20). En septiembre, Argentina y Brasil inician negociaciones con respecto a una alianza militar antisubversiva ("Alianza militar", Visión, vol. 29, no. 10, p. 16). Finalmente en diciembre, el entonces Secretario de Estado de EE.UU., Dean Rusk, presenta extraoficialmente ante la II Conferencia Especial Interamericana de Ministros de Relaciones Exteriores, la propuesta de crear-con carácter permanente-la Fuerza Interamericana de Paz. Dicha propuesta no resultó ser aprobada por la Conferencia ("Un final diplomático", Visión, vol. 30, no. 4, p. 17). página.

En el resto de las citas textuales de Los hombres de a caballo simplemente se mencionará la

7 A.A. Mendilow, "The Position of the Present in Fiction", ed. Philip Stevick, The Theory of the Novel. (New York: The Free Press, 1967), p. 271. 
de actualidad del pasado destaca la persistencia de la tradición militar que los ejércitos gauchos, anárquicos, del siglo diecinueve, ha legado a la Argentina moderna.

La irrisión de-esa herencia se manifiesta en la anómala afinidad entre hombres y caballos. El caballo es el único ser capaz de generar sentimientos de ternura en estos jinetes: "Pibe lindo-le decía (al caballo) -, mi querido, no se me ponga nervioso'. Incluso le toqueteaba las verijas, unas verijas rosadas y temblorosas secreteándole 'Usted a mí me deja tocarle ahí; al único que le deja' ", (p. 33). Por contraste, los jinetes son, fieles a la tradición gauchesca, misóginos: el caballo a veces se interpone-como rival-entre marido y mujer, y la bestialidad sexual del caballo sirve de estímulo apto para la emulación. El caballo se establece en la vida de estos hombres como encarnación de la virilidad y los hombres lo imitan hasta el punto de colocarse rellenos malolientes entre las piernas.

Es al llegar a estos extremos grotescos cuando resalta la parodia de Viñas: los hombres de a caballo se han convertido en pobres remedos de centauros clásicos ${ }^{8}$ La virilidad exagerada y la ausencia de mujeres alcanzan un momento de mayor humorismo cuando los cadetes del ejército ensayan el baile de gala de fin de curso. Como por supuesto, no hay mujeres, los cadetes se dividen en parejas en que uno, naturalmente, hace el papel del hombre, mientras que el otro, para desgracia suya, se ve obligado a hacer el papel de señorita de sociedad. En una realidad forzada, artificial como ésta, el macho, el remedo de centauro verbaliza su bestialidad sexual, su deseo de humillar y de violar.

El odio, la falsa superioridad que ostentan los jinetes, está basada y justificada por ser ellos los fundadores de la nación: "El ejército es lo previo y permanente: antes de la nación y sustancia de la nación" (p. 42). Ellos, los centauros, son anteriores a la madre, a la tierra; que luego sometieron y que les pertenece como una esposa o querida cualquiera. Esta actitud de macho omnipotente y autosuficiente determina la política del ejército: lo bueno para el ejército es bueno para la nación.

El enjuiciamiento trágico-cómico de la tradición militar ecuestre de Hispanoamérica se observa de otros modos. Estos centauros que han ido a Lima a poseer, a someter todo un continente a sus apetitos y designios, llegan a sentir envidia ante la popularidad del seleccionado argentino de fútbol con el que coinciden en la capital peruana, e incluso pretenden neutralizar a los atletas por medio de un desfile militar. Además, y muy a propósito del carácter rural del Operativo Ayacucho, se anticipa ya la rebelión a su autoridad en las zonas urbanas. Estas, resultado lejano de la violación inicial, son rencorosas y parricidas. Allí los centauros no tienen la más mínima relevancia o efectividad, como indica

8 Una de las primeras novelas gauchescas-mencionada con anterioridad-ya había descubierto el paralelo clásico: José Joaquín de Vedia, Aventuras de un centauro de la América meridional. (Buenos Aires: Imprenta del Orden, 1868). 
el episodio en que Godoy recoge a una mujer a la salida del cine y tiene que reconocerle que lo único que sabe hacer bien es "andar a caballo" (p. 23). Cualidad poco útil en una ciudad moderna.

Así como el viaje espacial de los centauros resulta un fracaso, el viaje temporal-genealógico pone de manifiesto la degeneración de la estirpe militar. En el último Godoy confluyen todos los pecados de la familia. Del tatarabuelo, que se distinguió peleando en la guerra de independencia, al bisabuelo que murió luchando contra Rosas, al abuelo que participó en la desatinada guerra del Chaco, llegamos al padre, que siempre ha sabido elegir la facción triunfarite en las intrigas castrenses, al tío que no ha salido tan afortunado en ese tipo de escaramuza, y al hermano mayor que, también por haber elegido mal, ha sido dado de baja del ejército, y - sintiéndose castrado-se suicida. Emilio, por su parte, tiene que reconocer sus defectos o limitaciones como esposo impotente, como amante demasiado tímido, e incluso como jinete que se deja dominar por su caballo.

La épica gauchesca, que había culminado en Don Segundo Sombra, que nos había dado toda una filosofía personal y política con aquello de "hacete duro, muchacho", ha dejado de ser viable, según Viñas, para la Argentina de hoy. El héroe tradicional ha derivado en unos "flojos" (los últimos Godoys); la historia avanza y los centauros pierden terreno. Aunque espoleen sus caballos, la novela de Viñas demuestra que su trayectoria ha alcanzado el fin. 
